\title{
Analisis Kemampuan Lahan Dan Kesuburan Tanah Pada Lahan Perencanaan Kebun Percobaan Universitas Muhammadiyah Sorong
}

\author{
Nurul Fajeriana M dan Ranti Wijaya \\ Universitas Muhammadiyah Sorong \\ nurfariana_miu2@yahoo.co.id
}

\begin{abstract}
Abstrak
Kebun percobaan merupakan salah satu unsur penunjang utama dalam kegiatan akademik pada Universitas Muhammadiyah Sorong. Tidak hanya peruntukannya untuk dosen tetapi juga untuk mahasiswa dalam melakukan praktikum, penelitian, pengkajian maupun pengembangan pertanian yang ada. Kebun percobaan pada fungsinya harus mendukung segala bentuk aktifitas dalam bidang akademik, terkhusus dalam ilmu pertanian. Dalam hal ini karakteristik lahan dan juga status hara sangat penting untuk dikaji sehingga diperoleh kebijakan dalam arah pemanfaatan lahan. Penelitian ini dilakukan selama 7 bulan yang berlangsung dari bulan April hingga Oktober 2020 dengan metode survey dan pengambil sampel tanah secara Simple Random Sampling di lahan perencanaan Kebun Percobaan Universitas Muhamadiyah Sorong di Jl. Arteri Kelurahan Malaingkeidi, Kecamatan Sawagumu Kota Sorong dan olah data kesuburan tanah berdasarkan analisis kimia tanah dari Laboratorium Kimia dan Kesuburan Tanah, Departemen Ilmu Tanah, Fakultas Pertanian, Universitas Hasanuddin. Dari hasil status hara memiliki unsur hara untuk pertumbuhan tanaman sangat rendah hingga sedang. Dan untuk Kelas Kemampuan Lahan masuk dalam kelas V dengan faktor pembatas genangan, iklim dan darinase tanah. Oleh karena itu diberikan rekomendasi perbaikan yakni dengan pembajakan dan perataan tanah, pembuatan gundukan atau bedengan serta penutupan tanah dengan bahan organik. Hal ini dimaksudkan agar dapat memaksimalkan penggunaan lahan untuk peruntukan pertanian yang lestari.
\end{abstract}

Kata kunci: Kebun_percobaan; UM-Sorong, kemampuan_lahan

\begin{abstract}
The experimental garden is one of the main supporting elements in academic activities at the Muhammadiyah University of Sorong. It is not only intended for lecturers but also for students in carrying out practicum, research, study, and agricultural development. In its function, the experimental garden must support all forms of activity in the academic field, especially in agricultural science. In this case, the characteristics of the land and also the nutrient status are very important to be studied in order to obtain policies on the direction of land use. This research was conducted for 7 months, which lasted from April to October 2020 using survey methods and simple random sampling of soil samples in the planning area of the Muhamadiyah University Sorong Experimental Garden on Arteri Malaingkeidi Village, Sawagumu District, Sorong City, and process soil fertility data based on soil chemical analysis from the Chemical and Soil Fertility Laboratory, Department of Soil Science, Faculty of Agriculture, Hasanuddin University. From the results, the nutrient status has very low to moderate
\end{abstract}


nutrient elements for plant growth. And for the Land Ability Class, it is included in class $V$ with the limiting factor of inundation, climate, and land degradation. Therefore, recommendations for improvement are given, namely by plowing and leveling the soil, making mounds or raised beds, and covering the soil with organic matter. This is intended to maximize land use for sustainable agricultural purposes.

Keywords: Experiment_yard; UM-Sorong, land_capability

\section{PENDAHULUAN}

Tanah sebagai media tanam tidak begitu saja menunjang keberhasilan usaha pertanian yang dilakukan. Ada banyak faktor pada tanah yang dapat mempengaruhi layak tidaknya untuk dipergunakan sebagai lahan pertanian. Seperti halnya pada kemampuan lahan. Lahan merupakan suatu sistem yang kompleks, tidak hanya tentang karakteristik lahan tetapi juga pada kualitas lahan itu sendiri yakni menyangkut status hara yang ada di dalamnya.

Penggolongan lahan ke dalam suatu kategori kemampuan lahan mengacu pada faktor pembatas yang dimiliki oleh satuan-satuan lahan. Perhatian utama yang diawali pada pengklasifikasian lahan untuk kepentingan pertanian serta kemungkinan tindakan konservasi yang perlu dilakukan. Kemampuan lahan didasarkan atas pertimbangan keadaan biofisik lahan dan pengelolaannya sehingga tidak terjadi degradasi lahan selama digunakan atau dalam hal ini tujuan lestarinya tercapai. Klasifikasi kemampuan lahan dilakukan dengan metode faktor pembatas atau penghambat. Dengan metode ini setiap kualitas lahan atau sifat-sifat lahan diurutkan dari yang terbaik sampai yang terburuk atau dari yang paling kecil hambatan atau ancamannya sampai yang terbesar, dengan kata lain, semakin besar hambatan maka semakin rendah kelasnya yang menunjukkan intensitas penggunaan lahan semakin menurun. Fajeriana (2018) mengemukakan bahwa lahan merupakan salah satu jenis sumber daya alam yang relatif tidak terbaharui sehingga harus dimanfaatkan sesuai dengan potensi dan daya dukung yang dimiliki lahan tersebut.

Lahan yang ada tidak hanya membahas tentang karakteristiknya demi menunjang suatu keberlanjutan tetapi satus hara juga menjadi faktor utama yang tidak bisa dikesampingkan. Hal ini dikarenakan, ketersediaan unsur-unsur hara yang ada dalam tanah dapat digunakan oleh tanaman dalam pertumbuhan dan perkembangannya. Penelitian tentang kemampuan lahan banyak dilakukan agar penggunaan akan lahan bisa lestari, Hartanto (2017), yang melakukan penelitian pada DAS Jono Kabupaten Bantul Yogyakarta menemukan bahwa dari total 523 Ha, lahan yang penggunaannya sesuai memiliki luas $184 \mathrm{Ha}$, sedangkan yang tidak sesuai dengan kemampuan lahannya memiliki luas $329 \mathrm{Ha}$, dari sinilah perbandingan lahan yang diberdayakan dengan tidak sesuai kemampuannya akan berdampak buruk dan tidak ada keberlanjutan sehingga malah merusak ekosistem yang ada, termasuk tanah yang ada pada lahan tersebut.

Tanah yang subur adalah tanah yang mempunyai profil yang dalam (kedalaman /solum sangat dalam melebihi $150 \mathrm{~cm}$ ). Strukturnya gembur, $\mathrm{pH}$ 6,0-6,5; kandungan unsur haranya yang tersedia bagi tanaman adalah cukup; dan tidak terdapat faktor 
pembatas dalam tanah untuk pertumbuhan tanaman (Sutedjo, 2002). Prabowo dkk. (2018) melakukan penelitian tetang tingkat kesuburan lahan budidaya pertanian di Kota Semarang, yang berada pada kategori sangat rendah sampai rendah sehingga dari data ini petani bisa menaikkan status hara tanah dengan pemberian pupuk sesuai kebutuhan hara tanaman.

Analisis kesuburan tanah adalah suatu cara dalam menilai status hara yang ada dalam tanah sehingga membantu dalam merekomendasikan penentuan jenis tanaman dan rekomendasi pemupukuan yang tepat. Menurut Anna dkk dalam Yamani (2010), Kesuburan tanah adalah potensi tanah untuk menyediakan unsur hara dalam jumlah yang cukup dalam bentuk tersedia dan seimbang untuk menjamin pertumbuhan dan produksi tanaman yang optimum.

Universitas Muhammadiyah Sorong adalah institusi pendidikan yang ada di Provinsi Papua Barat tepatnya di Kota Sorong. Dalam rangka mewujudkan visi misinya maka dalam hal ini telah merencanakan suatu lahan untuk dijadikan Kebun Percobaan bagi Fakultas Pertanian. Kebun percobaan merupakan salah satu unsur penunjang utama dalam kegiatan akademik pada suatu institusi pendidikan. Tidak hanya peruntukannya untuk dosen tetapi juga untuk mahasiswa dalam melakukan praktikum, penelitian, pengkajian maupun pengembangan pertanian yang ada.

Kebun percobaan pada fungsinya harus mendukung segala bentuk aktifitas dalam bidang akademik, terkhusus dalam ilmu pertanian. Perencanaan peruntukan lahan harus didasarkan atas kemampuan lahan yang dimiliki. Dalam hal ini karakteristik lahan dan juga status hara sangat penting untuk dikaji. Maka dari itu dilakukan penelitian untuk menentukan kelas kemapuan lahan dan kesuburan tanah untuk lahan perencanaan Kebun Percobaan Universitas Muhammadiyah Sorong yang berlokasi di Kelurahan Malaingkeidi, Kecamatan Malaimsimsa Kota Sorong.

\section{METODE PENELITIAN}

Pelaksanaan penelitian ini dilakukan pada bulan April hingga Oktober 2020 di lahan perencanaan Kebun Percobaan Universitas Muhamadiyah Sorong di Jl. Arteri Kelurahan Malaingkeidi, Kecamatan Sawagumu Kota Sorong dengan metode survey dan pengambilan sampel tanah secara Simple Random Sampling serta analisis sampel tanah pada laboratorium Kimia dan Kesuburan Tanah, Departemen Ilmu Tanah Fakultas Pertanian Universitas Hasanuddin Makassar.

\section{Tahapan Penelitian}

Tahapan-tahapan penelitian anatara lain:

1. Pengolahan data curah hujan 10 tahun terakhir degan perhitungan hujan rata-rata. Penetapan tipe iklim menurut klasifikasi Schmidt-Ferguson dan Oldeman.

2. Pembuatan Peta Kerja dengan hasil foto udara existing lahan perencanaan Kebun Percobaan UMS.

3. Pengukuran titik pengambilan sampel tanah dengan Simple Random Sampling yang mengacu pada satu lahan dengan kemiringan lereng dan jenis tanaman yang tumbuh 
berbeda, agar setiap sampel tanah yang diambil dapat mewakili total keselurahan luas lahan yang ada. Sampel tanah yang diambil setidaknya ada 8 sampel tanah dengan total luas $2400 \mathrm{~m}^{2}$.

4. Survei lapangan dan pengambilan sampel tanah. Survei ini merupakan survey observasi lapangan dengan menentukan titik koordinat pengambilan sampel tanah di lapangan. Pengambilan sampel tanah yang dilakukan dengan sampel tanah terganggu yakni dengan cara membersihkan tutupan lahan jika ada lalu menancapkan bor tanah dari top soil (lapisan permukaan tanah) hingga pada kedalaman tertentu dengan kurang lebih masing-masing $1 \mathrm{~kg}$ sampel tanah di tiap titik pengambilan.

5. Pengamatan area sekitar pada masing-masing titik pengambilan sampel dan hasilnya dituliskan dalam Daftar Isian Profil (DIP) berupa bentuk wilayah, vegetasi, kondisi drainase tanah, kedalaman tanah, tingkat bahaya banjir, struktur tanah, tekstur tanah, konsistensi tanah, kondisi batuan dipermukaan dan tingkat erosi.

6. Analisis tanah di Laboratorium untuk mengetahui sifat kimia dan kesuburan tanah. Sampel tanah yang telah diambil kemudian dikeringudarakan lalu dianalisis. Analisis sampel tanah yang dilakukan yakni:

a) Tekstur tanah ditetapkan dengan metode Hydrometer.

b) Kapasitas Tukar Kation (KTK) ditetapkan dengan penjenuhan $\mathrm{NH}_{4} \mathrm{OAc}$.

c) Kemasaman tanah $(\mathrm{pH})\left(\mathrm{H}_{2} \mathrm{O}\right.$ 1:2,5) dengan $\mathrm{pH}$ meter.

d) C-organik dengan metode Walkey dan Black

e) $\mathrm{P}_{2} \mathrm{O}_{5}$ tersedia dalam ppm dengan metode Bray L.

f) $\mathrm{N}$ total, dengan metode Kjedhahl.

g) Kejenuhan Basa

7. Olah data kesuburan tanah, berdasarkan hasil analisis kimia dan kesuburan tanah, dilakukan penilaian status hara yang merujuk pada petunjuk teknis evaluasi kesuburan tanah Pusat Penelitian Tanah, Bogor (PPT, 1995).

8. Penentuan kelas kemampuan lahan. Penentuan kelas kemampuan lahan dilakukan berdasarkan data iklim,

9. hasil pengamatan dilapangan, dan analisis laboratorium dari tiap titik sampel tanah yang diambil. Parameter yang diamati kemudian dicocokkan dengan kriteria klasifikasi kemampuan lahan baik secara fisik maupun kimianya dan juga faktor pembatas yang ada.

\section{HASIL DAN PEMBAHASAN}

Berdasarkan hasil penelitian yang telah dilakukan dengan olah data curah hujan dan suhu untuk penentuan iklim, metode survey dan pengambilan sampel tanah di lahan rencana Kebun Percobaan Universitas Muhammadiyah Sorong dan analisis contoh tanah pada laboratorium Kimia dan Kesuburan Tanah, Departemen Ilmu Tanah Fakultas Pertanian Universitas Hasanuddin Makassar, maka diperoleh hasil sebagai berikut:

\section{Iklim}

1. Pengolahan data curah hujan dan suhu udara 10 tahun terakhir untuk penetapan 
iklim dan kategori daerah menurut:

a) Klasifikasi Schmidt_Ferguson yakni Kelurahan Sawagumu Kecamatan Malaimsimsa termasuk Tipe Iklim A, yakni sangat basah;

b) Klasifikasi tipe iklim menurut Oldeman yakni Kelurahan Sawagumu termasuk Tipe Iklim C, yakni daerah yang cocok untuk dibudidayakan padi sawah.

c) Iklim menurut Junghuhn yakni berdasarkan suhu rata-rata Kelurahan Sawagumu maka termasuk dalam kategori Daerah Panas/Tropis yang bisa ditanami padi, jagung, kopi, tembakau, tebu, karet, kelapa.

\section{Peta Kerja}

Pembuatan peta kerja yang dimana teknik pengambilan sampel (contoh) tanah dilakukan dengan Simple Random Sampling yang mengacu pada suatu lahan dengan kemiringan lereng dan jenis tanaman yang tumbuh berbeda agar setiap sampel tanah yang diambil mewakili total keseluruhan lahan yang ada yakni sebanyak 8 titik pengamatan dan pengambilan sampel (contoh tanah terganggu) pada luas lahan 2400 $\mathrm{m}^{2}$.

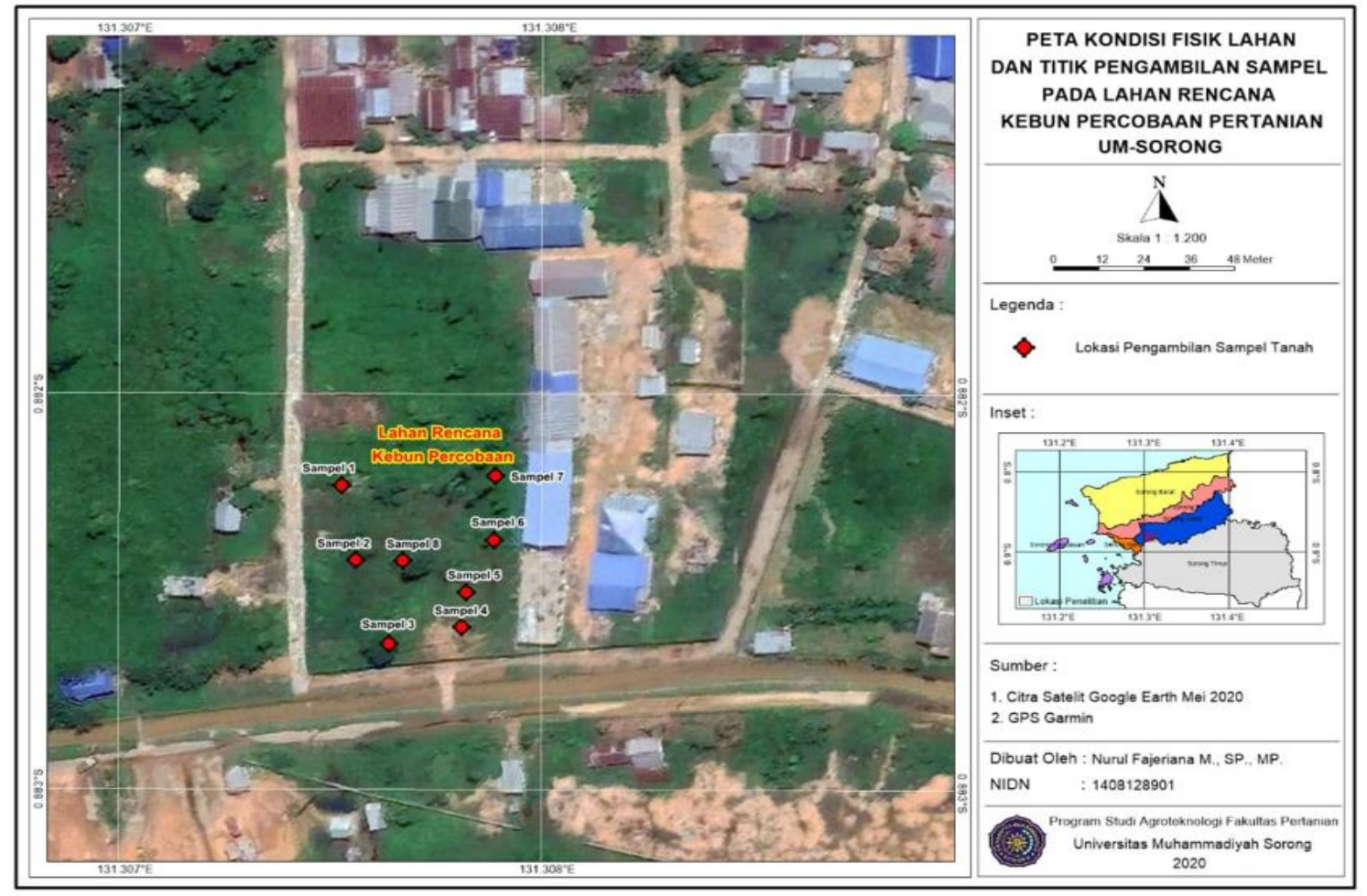

Gambar 1. Peta Kondisi Fisik Lahan dan Titik Pengambilan Sampel Tanah Pada Lahan Rencana Kebun Percobaan Pertanian Universitas Muhammadiyah Sorong.

\section{Kesuburan Tanah}

Berdasarkan data analisis sampel tanah dari Laboratorium selanjutnya dilakukan penilaian satus hara yang merujuk pada petunjuk teknis evaluasi kesuburan tanah Pusat Penelitian Tanah, Bogor (PPT, 1995) dalam Prabowo (2017), yang dapat dilihat pada tabel berikut ini: 


\section{Median Volume 12 Nomor 3 Bulan Oktober 2020}

Doi http://doi.org/md.v12i3.791

Tabel 1. Status hara tanah pada Lahan Rencana Kebun Percobaan UM-Sorong

\begin{tabular}{|c|c|c|c|c|c|c|c|c|c|c|c|}
\hline SPT & Tekstur & pH & C-Organik & $\mathbf{N}$ & $\mathrm{P}_{2} \mathrm{O}_{5}$ (Olsen) & $\mathbf{K}$ & $\mathrm{Ca}$ & Mg & $\mathrm{Na}$ & KTK & KB \\
\hline Profil 1 & $\begin{array}{c}\text { Liat } \\
\text { berpasir }\end{array}$ & $\begin{array}{c}5,42 \\
\text { (masam) }\end{array}$ & $\begin{array}{c}1,68 \\
\text { (rendah) }\end{array}$ & $\begin{array}{c}0,12 \\
\text { (rendah) }\end{array}$ & $\begin{array}{c}5,58 \\
\text { (sangat rendah) }\end{array}$ & $\begin{array}{c}0,21 \\
\text { (rendah) }\end{array}$ & $\begin{array}{c}6,27 \\
\text { (sedang) }\end{array}$ & $\begin{array}{c}0,88 \\
\text { (rendah) }\end{array}$ & $\begin{array}{c}0,16 \\
\text { (rendah) }\end{array}$ & $\begin{array}{c}21,49 \\
\text { (sedang) }\end{array}$ & $\begin{array}{c}35 \\
\text { (rendah) }\end{array}$ \\
\hline Profil 2 & Liat & $\begin{array}{c}5,96 \\
\text { (agak masam) }\end{array}$ & $\begin{array}{c}2,05 \\
\text { (sedang) }\end{array}$ & $\begin{array}{c}0,10 \\
\text { (rendah) }\end{array}$ & $\begin{array}{c}8,65 \\
\text { (sangat rendah) }\end{array}$ & $\begin{array}{c}0,16 \\
\text { (rendah) }\end{array}$ & $\begin{array}{c}5,79 \\
\text { (sedang) }\end{array}$ & $\begin{array}{c}2,18 \\
\text { (tinggi) }\end{array}$ & $\begin{array}{c}0,14 \\
\text { (rendah) }\end{array}$ & $\begin{array}{l}25,26 \\
\text { (tinggi) }\end{array}$ & $\begin{array}{c}33 \\
\text { (rendah) }\end{array}$ \\
\hline Profil 3 & $\begin{array}{c}\text { Lempung } \\
\text { liat } \\
\text { berdebu }\end{array}$ & $\begin{array}{c}5,42 \\
\text { (masam) }\end{array}$ & $\begin{array}{c}1,59 \\
\text { (rendah) }\end{array}$ & $\begin{array}{c}0,14 \\
\text { (rendah) }\end{array}$ & $\begin{array}{l}10,35 \\
\text { (rendah) }\end{array}$ & $\begin{array}{c}0,22 \\
\text { (rendah) }\end{array}$ & $\begin{array}{c}4,73 \\
\text { (rendah) }\end{array}$ & $\begin{array}{c}2,42 \\
\text { (tinggi) }\end{array}$ & $\begin{array}{c}0,22 \\
\text { (rendah) }\end{array}$ & $\begin{array}{c}22,62 \\
\text { (sedang) }\end{array}$ & $\begin{array}{c}34 \\
\text { (rendah) }\end{array}$ \\
\hline Profil 4 & $\begin{array}{c}\text { Lempung } \\
\text { liat } \\
\text { berpasir }\end{array}$ & $\begin{array}{c}5,32 \\
\text { (masam) }\end{array}$ & $\begin{array}{c}2,57 \\
\text { (sedang) }\end{array}$ & $\begin{array}{c}0,18 \\
\text { (rendah) }\end{array}$ & $\begin{array}{c}7,21 \\
\text { (sangat rendah) }\end{array}$ & $\begin{array}{c}0,17 \\
\text { (rendah) }\end{array}$ & $\begin{array}{c}7,15 \\
\text { (sedang) }\end{array}$ & $\begin{array}{c}1,76 \\
\text { (sedang) }\end{array}$ & $\begin{array}{c}0,21 \\
\text { (rendah) }\end{array}$ & $\begin{array}{l}25,63 \\
\text { (tinggi) }\end{array}$ & $\begin{array}{c}36 \\
\text { (sedang) }\end{array}$ \\
\hline Profil 5 & Liat & $\begin{array}{c}5,73 \\
\text { (agak masam) }\end{array}$ & $\begin{array}{c}1,92 \\
\text { (rendah) }\end{array}$ & $\begin{array}{c}0,12 \\
\text { (rendah) }\end{array}$ & $\begin{array}{c}7,86 \\
\text { (sangat rendah) }\end{array}$ & $\begin{array}{c}0,15 \\
\text { (rendah) }\end{array}$ & $\begin{array}{c}5,30 \\
\text { (sedang) }\end{array}$ & $\begin{array}{c}2,44 \\
\text { (tinggi) }\end{array}$ & $\begin{array}{c}0,19 \\
\text { (rendah) }\end{array}$ & $\begin{array}{c}24,12 \\
\text { (sedang) }\end{array}$ & $\begin{array}{c}34 \\
\text { (rendah) }\end{array}$ \\
\hline Profil 6 & Liat & $\begin{array}{c}5,68 \\
\text { (agak masam) }\end{array}$ & $\begin{array}{c}1,87 \\
\text { (rendah) }\end{array}$ & $\begin{array}{c}0,11 \\
\text { (rendah) }\end{array}$ & $\begin{array}{c}8,65 \\
\text { (sangat rendah) }\end{array}$ & $\begin{array}{c}0,17 \\
\text { (rendah) }\end{array}$ & $\begin{array}{c}5,19 \\
\text { (sedang) }\end{array}$ & $\begin{array}{c}0,64 \\
\text { (rendah) }\end{array}$ & $\begin{array}{c}0,32 \\
\text { (rendah) }\end{array}$ & $\begin{array}{c}22,09 \\
\text { (sedang) }\end{array}$ & $\begin{array}{c}27 \\
\text { (rendah) }\end{array}$ \\
\hline Profil 7 & $\begin{array}{l}\text { Lempung } \\
\text { berpasir }\end{array}$ & $\begin{array}{c}5,69 \\
\text { (agak masam) }\end{array}$ & $\begin{array}{c}2,76 \\
\text { (sedang) }\end{array}$ & $\begin{array}{c}0,12 \\
\text { (rendah) }\end{array}$ & $\begin{array}{c}7,75 \\
\text { (sangat rendah) }\end{array}$ & $\begin{array}{c}0,16 \\
\text { (rendah) }\end{array}$ & $\begin{array}{c}5,46 \\
\text { (sedang) }\end{array}$ & $\begin{array}{c}2,57 \\
\text { (tinggi) }\end{array}$ & $\begin{array}{c}0,21 \\
\text { (rendah) }\end{array}$ & $\begin{array}{c}21,60 \\
\text { (sedang) }\end{array}$ & $\begin{array}{c}39 \\
\text { (sedang) }\end{array}$ \\
\hline Profil 8 & Liat & $\begin{array}{c}5,82 \\
\text { (agak masam) }\end{array}$ & $\begin{array}{c}2,96 \\
\text { (sedang) }\end{array}$ & $\begin{array}{c}0,14 \\
\text { (rendah) }\end{array}$ & $\begin{array}{c}5,24 \\
\text { (sangat rendah) }\end{array}$ & $\begin{array}{c}0,12 \\
\text { (rendah) }\end{array}$ & $\begin{array}{c}4,29 \\
\text { (rendah) }\end{array}$ & $\begin{array}{c}1,39 \\
\text { (sedang) }\end{array}$ & $\begin{array}{c}0,24 \\
\text { (rendah) }\end{array}$ & $\begin{array}{c}20,96 \\
\text { (sedang) }\end{array}$ & $\begin{array}{c}29 \\
\text { (rendah) }\end{array}$ \\
\hline
\end{tabular}

Sumber: Data Primer setelah diolah, 2020.

Dari tabel status hara pada lahan perencanaan kebun percobaan UM-Sorong memiliki unsur hara untuk pertumbuhan tanaman sangat rendah hingga sedang, oleh karena itu, jika akan dijadikan sebagai Kebun Percobaan Fakultas Pertanian disarankan untuk melakukan pemupukan dengan pemberian bahan organik di atas tanah dan isolasi lahan selama kurang lebih 1 tahun. Dengan penambahan bahan organik diharapkan akan meningkatkan unsur hara makro dan mikro dalam tanah yang dapat digunakan untuk tanaman agar optimal dalam pertumbuhan dan perkembangannya perkembangannya. Hal ini sesuai dengan Widyantari (2015), yang menyatakan bahwa kandungan Corganik (bahan organik) tanah sangat berpengaruh terhadap kemampuan tanah dalam mempertahankan kesuburan dan produktivitas tanah melalui aktivitas mikroorganisme tanah. Selain itu menurut Fajeriana (2018), Faktor pembatas unsur hara P $\left(\mathrm{P}_{2} \mathrm{O}_{5}\right), \mathrm{C}-$ Organik, dan N-total serta daya menahan unsur hara ( $\mathrm{pH}$ tanah dan KTK), dapat diatasi dengan pemberian pupuk dan pengapuran sehingga peningkatan kesesuaian lahan potensial dapat diperoleh. Peran bahan organik bagi tanah merupakan pembentuk granulasi dalam tanah dan sangat pentting dalam pembentukan agregat tanah yang stabil (Tolaka, 2013).

\section{Kelas Kemampuan Lahan}


Berdasarkan hasil pengamatan lapangan kelas kemampuan lahan untuk tiap profil untuk lahan rencana kebun percobaan Universitas Muhammadiyah Sorong dapat dilihat pada tabel berikut ini:

Tabel 2. Kelas Kemampuan Lahan Lahan Perencaan Kebun Percobaan UM Sorong Beserta Rekomendasi Perbaikan.

\begin{tabular}{|c|c|c|c|c|}
\hline $\begin{array}{c}\text { Unit } \\
\text { Lahan }\end{array}$ & $\begin{array}{c}\text { Kelas } \\
\text { Kemampuan } \\
\text { Lahan }\end{array}$ & Faktor Pembatas & $\begin{array}{l}\text { Hasil Evaluasi } \\
\text { Kelas Lahan }\end{array}$ & $\begin{array}{c}\text { Rekomendasi } \\
\text { Perbaikan }\end{array}$ \\
\hline Profil 1 & IIt-2 & Tekstur tanah $(\mathrm{t})$ & \multirow{8}{*}{ Vwcd } & \multirow{8}{*}{$\begin{array}{c}\text { Pembajakan dan } \\
\text { perataan tanah, } \\
\text { pembuatan } \\
\text { gundukan atau } \\
\text { bedengan serta } \\
\text { penutupan tanah } \\
\text { dengan bahan } \\
\text { organik. }\end{array}$} \\
\hline Profil 2 & Vw-3 & Banjir/genangan (w) & & \\
\hline Profil 3 & IIId- & Drainase tanah (d) & & \\
\hline Profil 4 & IIId-3 & Drainase tanah $(\mathrm{d})$ & & \\
\hline Profil 5 & IIId-2 & Permeabilitas (p) & & \\
\hline Profil 6 & Vwc-3 & Iklim (c) dan banjir (w) & & \\
\hline Profil 7 & Vwc-4 & Iklim (c) dan banjir (w) & & \\
\hline Profil 8 & IIIp-3 & Permeabilitas (p) & & \\
\hline
\end{tabular}

Sumber: Data primer setelah diolah, 2020.

Dari tabel tersebut dapat kita lihat bahwa Kelas Kemampuan Lahan Rencana Kebun Percobaan Universitas Muhammadiyah Sorong yang terletak di Kelurahan Sawagumu Kecamatan Malaimsimsa masuk dalam kelas V dengan faktor pembatas genangan, iklim dan darinase tanah. Menurut Arsyad (1979) dalam Liansari (2012) bahwa tanah-tanah pada lahan kelas $\mathrm{V}$ tidak terancam erosi karena memiliki topografi yang datar tetapi sering tergenang air namun mempunyai hambatan yang tidak mudah untuk dihilangkan sehingga membatasi pilihan dalam penggunaannya. Oleh karena itu diberikan rekomendasi perbaikan yakni dengan pembajakan dan perataan tanah, pembuatan gundukan atau bedengan serta penutupan tanah dengan bahan organik. Hal ini dimaksudkan agar dapat memaksimalkan penggunaan lahan untuk peruntukan pertanian. Sebab, untuk lahan-lahan yang masuk dalam kategori V termasuk lahan marginal yang membutuhkan penanganan intensif yang peruntukannya sebagai lahan pertanian sudah menurun. Hal yang sama dikemukakan Hardjowigeno dan Widiatmaka (2007) oleh bahwa semakin tinggi kelas kemampuan lahannya berarti semakin sedikit peruntukan penggunaan pada lahan tersebut. Hal ini juga sejalan dengan Rayes (2007), bahwa semakin tinggi kelasnya maka semakin rendah kualitas lahannya. Setelah melalukan rekomendasi perbaikan, lahan ini berpotensi naik ke kelas II dengan arahan pertanian intensif. Hal ini disebabkan karena Kawasan lahan perencaan kebun percobaan ini telah ditimbuni sejak lama dengan material berpasir dari bahan induk Tuf andesitik, namun karena tidak diratakan dengan baik sehingga ada bagian yang tergenang. Perataan tanah sangat penting agar penggunaan lahan pada kawasan yang sama menjadi homogen sehingga produktivitas lahannya lebih intensif. Sitorus (2010), menyatakan bahwa suatu lahan yang homogen memiliki deskripsi yang lebih sederhana dan perbaikan kualitas tidak mengharuskan teknik konservasi yang rumit dan besar, sehingga pemanfaatan lebih optimal. Fajeriana (2020), menambahkan bahwa Perencaan 
peruntukan lahan merupakan suatu konsep yang utuh dan terintegrasi sehingga suatu lahan harus dioptimalkan agar tujuan lestarinya tercapai.

\section{KESIMPULAN}

Berdasarkan hasil penelitian yang telah dilakukan, dapat disimpulkan bahwa status kesuburan tanah pada lahan perencanaan Kebun Percobaan Universitas Muhammadiyah Sorong di Kelurahan Sawagumu Kecamatan Malaimsimsa Kota Sorong berada dalam status rendah sampai sedang. Sedangkan untuk kelas kemampuan lahannya berada pada kelas $\mathrm{V}$ dengan factor penghambat yakni genangan, iklim, dan drainase, sehinggadiberikan arahan rekomendasi perbaikan dengan pembajakan dan perataan tanah, pembuatan gundukan atau bedengan serta penutupan tanah dengan bahan organik agar bisa menaikkan kelas kemampuan lahannya dan optimal untuk dijadikan Kebun Percobaan.

\section{DAFTAR PUSTAKA}

Fajeriana, N. 2018. Evaluasi Kesesuaiaan Lahan Untuk Komoditas Pertanian di Kecamatan Polombangkeng Utara Kabupaten Takalar. Median: Jurnal Ilmu-Imu Eksakta UMS, 10(1):9-17.

Fajeriana N. \& Kadir, M.A.A (2020). Mapping of Conservation Area Plan in North PolomBangkeng District, Takalar Regency, BioLink: Jurnal Biologi Lingkungan, Industri dan Kesehatan, Vol.7 (1): Hal. 97-105

Hardjowigeno, S dan Widiatmaka. 2007. Evaluasi Kesesuaian Lahan dan Perencanaan Tataguna Lahan. Gadjah Mada University Press, Yogyakarta.

Hantarto R. Kresnawan. 2017. Analisis Kemampuan Lahan Untuk Arahan Penggunaan Lahan Bidang Petanian di DAS Jono, Kecamatan Piyungan Kabupaten Bantul Daerah Istimewa Yogyakarta. Program Studi Geografi Fakultas Geografi Universitas Muhammadiyah Surakarta. Diambil dari halaman website: eprints.ums.ac.id. Diakses pada tanggal 16 Agustus 2019.

Liansari Tyas Okta Nita. 2012. Kelas kemampuan Lahan Pertanian Pasca Erupsi Merapi 2010 Di Dusun karanggeneng Purwobinangun Pakem Sleman. Skripsi. Program Studi Pendidikan Geografi. Fakultas Ilmu Sosial Universitas Negeri Yogyakarta.

Prabowo Rossi dan Renan Subantoro. 2017. Analisis Tanah Sebagai Indikator Tingkat

Kesuburan Lahan Budidaya Pertanian Di Kota Semarang. Jurnal Ilmiah Cendekia

Eksakta. Vol.2, No.2 E-ISSN: 2548-2122. LP2M Universitas Wahid Hasyim.

Rayes, M.L. 2007. Metode Inventarisasi Sumber Daya Lahan. Penerbit Andi Offset. Yogyakarta.

Sitorus RPS. (2010). Land Capability Classification for Land Evaluation: Review. Journal of Agriculture Land Resource, 4(2), 69-78.

Sutedjo, M.M. (2002). Pupuk dan Cara Penggunaan. Rineka Cipta, Jakarta.

Tolaka, W.2013. Sifat Fisik Tanah pada Hutan Primer, Agroforestri, dan Kebun Kakao

di Subdas Wera Saluopa, Desa Leboni, Kecamatan Pamona, Peselemba 
Kabupaten Poso. Jurusan Kehutanan. Fakultas Kehutanan Universitas Tadulako. Warta Rimba Vol.1, No.1.

Wdyantari Dyah A.G., Ketut Darma Susila, dan Tatik Kusumawati. 2015. Evaluasi Status Kesuburan Tanah untuk Lahan Pertanian di Kecamatan Denpasar Timur. E-Jurnal Agroteknologi Tropika.Vol. 4, No.4, ISSN: 2301-6515. Penerbit: Jurusan Agroteknologi Fakultas Pertanian Universitas Riau.

Yamani, A. 2010. Analisis Kadar Hara Makro dalam Tanah pada Tanaman Agroforestri di Desa Tambun Raya Kalimantan Tengah. Jurnal Hutan Tropis, 11 (30): 37-46. 